\title{
Risk perception and psychological state of healthcare workers in referral hospitals during the early phase of the COVID-19 pandemic, Uganda
}

Richard Migisha ${ }^{*}$, Alex Riolexus Ario ${ }^{1,2}$, Benon Kwesiga', Lilian Bulage ${ }^{1}$, Daniel Kadobera',

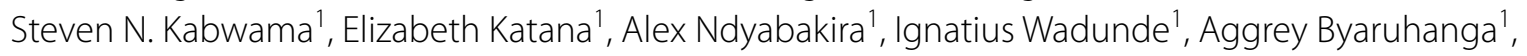
Geofrey Amanya', Julie R. Harris ${ }^{3}$ and Arthur G. Fitzmaurice ${ }^{3}$

\begin{abstract}
Background: Safeguarding the psychological well-being of healthcare workers (HCWs) is crucial to ensuring sustainability and quality of healthcare services. During the COVID-19 pandemic, HCWs may be subject to excessive mental stress. We assessed the risk perception and immediate psychological state of HCWs early in the pandemic in referral hospitals involved in the management of COVID-19 patients in Uganda.

Methods: We conducted a cross-sectional survey in five referral hospitals from April 20-May 22, 2020. During this time, we distributed paper-based, self-administered questionnaires to all consenting HCWs on day shifts. The questionnaire included questions on socio-demographics, occupational behaviors, potential perceived risks, and psychological distress. We assessed risk perception towards COVID-19 using 27 concern statements with a four-point Likert scale. We defined psychological distress as a total score > 12 from the 12-item Goldberg's General Health Questionnaire (GHQ-12). We used modified Poisson regression to identify factors associated with psychological distress.
\end{abstract}

Results: Among 335 HCWs who received questionnaires, 328 (98\%) responded. Respondents' mean age was 36 (range 18-59) years; 172 (52\%) were male. The median duration of professional experience was eight (range 1-35) years; 208 (63\%) worked more than 40 h per week; 116 (35\%) were nurses, 52 (14\%) doctors, 30 (9\%) clinical officers, and 86 (26\%) support staff. One hundred and forty-four (44\%) had a GHQ-12 score > 12. The most common concerns reported included fear of infection at the workplace (81\%), stigma from colleagues (79\%), lack of workplace support (63\%), and inadequate availability of personal protective equipment (PPE) (56\%). In multivariable analysis, moderate (adjusted prevalence ratio, $[\mathrm{aPR}]=2.2,95 \%$ confidence interval $[\mathrm{Cl}] 1.2-4.0$ ) and high (aPR $=3.8,95 \% \mathrm{Cl} 2.0-7.0$ ) risk perception towards COVID-19 (compared with low-risk perception) were associated with psychological distress.

Conclusions: Forty-four percent of HCWs surveyed in hospitals treating COVID-19 patients during the early COVID19 epidemic in Uganda reported psychological distress related to fear of infection, stigma, and inadequate PPE. Higher perceived personal risk towards COVID-19 was associated with increased psychological distress. To optimize

*Correspondence: rmigisha@musph.ac.ug

${ }^{1}$ Uganda Public Health Fellowship Program, Kampala, Uganda

Full list of author information is available at the end of the article

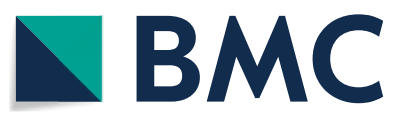

(C) The Author(s) 2021. Open Access This article is licensed under a Creative Commons Attribution 4.0 International License, which permits use, sharing, adaptation, distribution and reproduction in any medium or format, as long as you give appropriate credit to the original author(s) and the source, provide a link to the Creative Commons licence, and indicate if changes were made. The images or other third party material in this article are included in the article's Creative Commons licence, unless indicated otherwise in a credit line to the material. If material is not included in the article's Creative Commons licence and your intended use is not permitted by statutory regulation or exceeds the permitted use, you will need to obtain permission directly from the copyright holder. To view a copy of this licence, visit http://creativecommons.org/licenses/by/4.0/. The Creative Commons Public Domain Dedication waiver (http://creativeco $\mathrm{mmons}$.org/publicdomain/zero/1.0/) applies to the data made available in this article, unless otherwise stated in a credit line to the data. 
patient care during the pandemic and future outbreaks, workplace management may consider identifying and addressing HCW concerns, ensuring sufficient PPE and training, and reducing infection-associated stigma.

Keywords: COVID-19, Risk perception, Psychological distress, Healthcare workers, Uganda

\section{Introduction}

During major outbreaks, healthcare workers (HCWs) may experience high levels of psychological stress $[1,2]$. Depression, stress, anxiety, stigma arising from contracting infection, and concerns about infection including fear of infecting colleagues, friends, and family have all been reported previously among HCWs during the 2003 SARS outbreak [3-6] and during the Ebola Virus Disease outbreak in West Africa [7]. Such psychological distress can interfere with the effective implementation and sustainability of health services [8].

During the COVID-19 pandemic, an increased risk for short- and long-term mental health problems, including psychological distress has been reported among healthcare professionals involved in the management of patients with COVID-19 [9]. Recent evidence from various studies which have assessed the psychological impact of COVID-19 on HCWs, including systematic reviews, shows that psychological problems, such as psychological distress, insomnia, depression, and anxiety, have been very frequent among $\mathrm{HCWs}$ across the globe; prevalence estimates of these psychological problems that range from 39 to $71 \%$ have been reported [1, 9-14]. Nonetheless, most public health responses tend to focus primarily on the biological or physical effects of epidemics, ignoring the psychological effects of most disease outbreaks, despite the fact that the consequences are detrimental [15]. In low-income countries such as Uganda where there are limited human resources for health (approximately one skilled HCW for every 1000 persons as of 2019) [16], protecting the mental health of HCWs during outbreaks is especially important to ensure sustainability of healthcare services.

After confirming the first COVID-19 case in Uganda on March 21, 2020 [17], the number of confirmed COVID-19 cases increased to 212 with no deaths as of May 24, 2020 [18]. Although no HCWs in Uganda had been diagnosed with the disease at that time [18], there were widespread reports globally about HCWs who had contracted the disease and died [19-22]. HCWs were reportedly at higher risk both for disease and death [23, 24], and heightened tension and fear were anticipated among HCWs in Uganda. To understand more about potential psychological distress among HCWs in Uganda and recommend appropriate interventions, we assessed risk perception and immediate psychological state among HCWs with regard to the COVID-19 outbreak.

\section{Methods}

\section{Study design and population}

We conducted a cross-sectional survey from April 20May 22, 2020, in Central (Mulago National Referral Hospital, Entebbe Regional Referral Hospital), Eastern (Jinja Regional Referral Hospital), Western (Kabale Regional Referral Hospital), and Northern (Arua Regional Referral Hospital) regions of Uganda. At the time of this study, these hospitals were the only hospitals managing active COVID-19 case-patients. By the time the study began, the hospitals had managed 212 cases [18].

We designed a self-administered, structured questionnaire based on previous studies in outbreaks of respiratory infectious diseases, including COVID-19 in China [1, 25-27]. We chose a convenience sample of HCWs (doctors, clinical officers, nurses, midwives, radiographers, cleaners, drivers, administrators, laboratory personnel, and support staff) present on day-shift duties who consented to participate in the survey. The number of questionnaires distributed was based on the number of HCWs on duty in the respective hospitals (total of 335). Recruitment took one day in each referral hospital.

The principal investigator explained the study purpose and procedures to the HCWs in the respective departments and obtained written informed consent from all the participants prior to participation in the study. The participants indicated their consent by checking an appropriate box for consent before filling the questionnaire. The number of questionnaires distributed was based on the number of HCWs on duty, as determined by the respective heads of departments, in the respective hospitals. The questionnaires were returned by the heads of departments after $24 \mathrm{~h}$. HCWs were categorized as 'direct contact group' if their jobs involved direct contact with patients and 'indirect contact group' if they were in contact with patient-related items (e.g., biological specimens, equipment), as defined previously [27].

\section{Study variables and data collection instruments}

We captured data on HCWs' socio-demographic and occupational characteristics, concerns and attitudes regarding COVID-19, and their immediate psychological status. Data collected included age, sex, professional cadre, level of education, years of professional experience, number of hours worked per week, number of children, persons with whom the HCW resided, and whether 
the HCW had ever provided care to a suspected or confirmed COVID-19 patient.

We assessed risk perception towards COVID-19 using 27 concern statements related to fear of contracting COVID-19, fear of spreading COVID-19, workplacerelated conditions, and stigma. Each concern statement had four response options: 'strongly agree,' 'agree,' 'disagree,' or 'strongly disagree'. We applied a scoring system using a four-point Likert scale from zero points ('strongly disagree') to three points ('strongly agree'). Concern statements were negatively-worded (e.g., "there is no adequate personal protective equipment (PPE) at my workplace"), so that a higher score signified a higher degree of risk perception.

We used the 12-item General Health Questionnaire (GHQ-12) developed by Goldberg to assess the psychological state of HCWs [28]. The tool is multi-dimensional and has questions that assess social dysfunction, anxiety, and depression. The GHQ-12 has been widely used in assessing psychological state in outbreaks of infectious respiratory diseases (e.g., SARS and COVID-19) and found to have high reliability and validity $[1,5,29-31]$. The instrument includes 12 items (six negatively-worded and six positively-worded). The scoring method (from 0 to 36) is described elsewhere [32]. Briefly, we adopted the four-point Likert scale, with each item score ranging from ' 0 ' to ' 3 '. For negatively-worded items, ' 0 ' indicated 'Not at all, ' 1 ' indicated 'No more than usual', ' 2 ' indicated 'Rather more than usual' and ' 3 ' indicated 'Much more than usual. Positively-worded items were scored as follows: ' 0 ' indicated 'More so than usual, ' 1 ' indicated 'Same as usual,' '2' indicated 'Less so than usual', and ' 3 ' indicated 'Much less than usual'. All items were added to obtain the total score, ranging from 0 to 36 (with a higher score signifying worse mental health status). We classified respondents with scores greater than the cut-off point of 12 as having psychological distress, as previously described [33].

\section{Data management and statistical analysis}

We entered data into EpiData 3.1 (EpiData, Odense, Denmark) and exported it to STATA version 13 (Statacorp, College Station, Texas) for analysis. Categorical data were summarized by frequencies and percentages; continuous normally-distributed data (risk perception score and GHQ-12 score) were presented as means with standard deviations (SDs), and continuous non-normally-distributed data (hours worked, number of children) as medians with interquartile ranges.

We dichotomized responses to concern statements into non-concern (strongly disagree and disagree) and concern (strongly agree and agree). Respondents were categorized into three groups: low risk perception (at or below the first quartile of concern scores); moderate risk perception (in the second quartile); and high-risk perception (third and fourth quartiles), as used previously [27]. The prevalence of psychological distress was determined as the percentage of respondents with GHQ-12 score greater than 12 .

Finally, we performed univariable and multivariable analyses with psychological distress as a binary outcome to identify factors associated with psychological distress among HCWs. We considered risk perception among HCWs as our main exposure variable of interest and adjusted for other variables, including duration of professional experience, contact with confirmed COVID-19 case, and sex as potential confounders.

We reported prevalence ratios (PRs) with corresponding 95\% confidence intervals (CIs) as measures of association between psychological distress and associated factors. We obtained PRs via modified Poisson regression, using a generalized linear model with Poisson as family and a log link without an offset but including robust standard errors. We did not use odds ratios as the measures of association because they could potentially overestimate the effect given the high prevalence of our outcome variable.

\section{Results \\ Socio-demographics}

Among $335 \mathrm{HCWs}$ who received questionnaires, 328 (98\%) completed and returned them. The remaining seven HCWs returned the questionnaires unfilled; none of the HCWs declined. Respondents' mean age was $36(\mathrm{SD} \pm 9.9)$ years and ranged from 18 to 59 years. Approximately half were male and half female. More than one-third had fewer than five years of work experience (median eight years, range 1-35 years), and threequarters worked in direct contact with patients. Most worked more than $40 \mathrm{~h}$ per week (63\%) (median 50, range 24-104) and had a child or children (69\%). Approximately half reported ever providing direct care to suspected (57\%) or confirmed (46\%) COVID-19 cases at the time of study early in the pandemic (Table 1).

\section{Level of perceived risk towards COVID-19}

The possible range of total concern scores reported by our respondents was $0-81$ points. The mean risk perception score derived from the concern statements was $42(\mathrm{SD} \pm 12)$, ranged from 4 to 79 points, and was normally-distributed (Fig. 1). For the direct contact group $(n=242)$, the mean score was $42(S D \pm 12)$, while for the indirect contact group $(n=86)$ the mean score was 43 $(\mathrm{SD} \pm 11)$.

The greatest concerns of the group were about exposure to or illness with COVID-19, reflected in feeling 
Table 1 Characteristics of respondents during a study to assess the psychological impact of COVID-19 on healthcare workers early in the COVID-19 epidemic, Uganda $(\mathrm{N}=328)$

\begin{tabular}{|c|c|c|}
\hline \multirow[t]{2}{*}{ Characteristic } & \multicolumn{2}{|c|}{ Total $(\mathrm{N}=328)$} \\
\hline & Number & Percent \\
\hline \multicolumn{3}{|l|}{ Health facility location } \\
\hline Jinja & 88 & 27 \\
\hline Entebbe & 81 & 25 \\
\hline Arua & 72 & 22 \\
\hline Kabale & 57 & 17 \\
\hline Mulago & 30 & 9.1 \\
\hline \multicolumn{3}{|l|}{ Age in years } \\
\hline $18-35$ & 174 & 53 \\
\hline$\geq 36$ & 154 & 47 \\
\hline \multicolumn{3}{|l|}{ Sex } \\
\hline Male & 172 & 52 \\
\hline Female & 156 & 48 \\
\hline \multicolumn{3}{|l|}{ Cadre of healthcare workers } \\
\hline Nurse & 116 & 35 \\
\hline Support staff* & 86 & 26 \\
\hline Doctor & 52 & 14 \\
\hline Clinical officer & 30 & 9.0 \\
\hline Midwife & 21 & 6.4 \\
\hline Laboratory personnel & 17 & 5.2 \\
\hline Pharmacist & 5 & 1.5 \\
\hline Radiographer & 1 & 0.3 \\
\hline \multicolumn{3}{|l|}{ Category by patient contact } \\
\hline Direct contact group & 242 & 74 \\
\hline Indirect contact group & 86 & 26 \\
\hline Had provided direct care to suspected COVID-19 case & 186 & 57 \\
\hline Had provided direct care to confirmed COVID-19 case & 151 & 46 \\
\hline \multicolumn{3}{|l|}{ Years of experience } \\
\hline$<5$ & 124 & 38 \\
\hline $5-10$ & 89 & 27 \\
\hline$>10$ & 115 & 35 \\
\hline \multicolumn{3}{|l|}{ Hours worked per week } \\
\hline$\leq 40$ & 120 & 37 \\
\hline$>40$ & 208 & 63 \\
\hline \multicolumn{3}{|l|}{ Highest level of qualification } \\
\hline None & 11 & 3.4 \\
\hline Certificate & 77 & 23 \\
\hline Diploma & 101 & 31 \\
\hline Degree & 110 & 34 \\
\hline Masters & 15 & 4.6 \\
\hline Others (Post-Masters' and PhD Fellowships) & 14 & 4.3 \\
\hline \multicolumn{3}{|l|}{ Marital status } \\
\hline Single & 120 & 36 \\
\hline Married/living with a partner & 199 & 61 \\
\hline Separated/divorced & 9 & 2.7 \\
\hline Has child or children & 225 & 69 \\
\hline \multicolumn{3}{|l|}{ With whom the healthcare worker stays at home } \\
\hline Family & 212 & 65 \\
\hline Alone & 90 & 27 \\
\hline Others & 26 & 7.9 \\
\hline
\end{tabular}

Table 1 (continued)

*Support staff included cleaners, ambulance drivers, and administrators

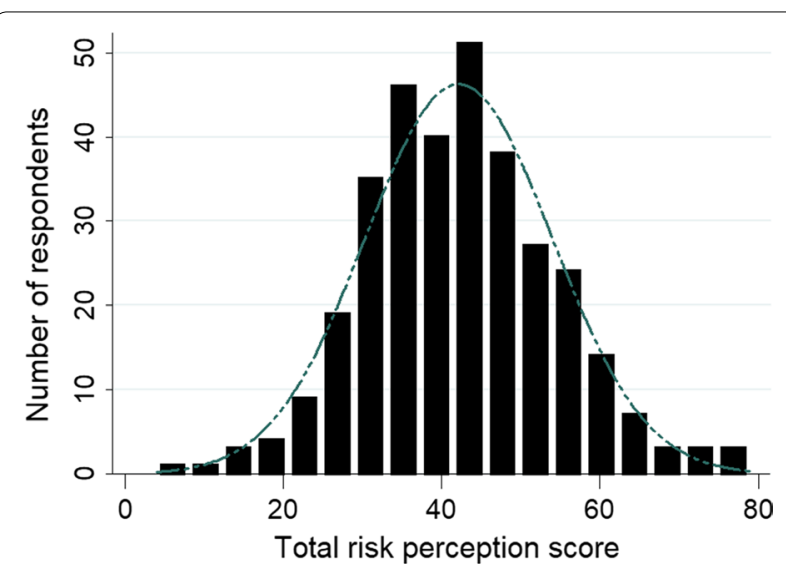

Fig. 1 Distribution of total risk perception score derived from concern statements in tertiary referral hospitals during the early phase of the COVID-19 epidemic, Uganda, April-May 2020 ( $N=328)$. Note: Higher risk perception scores signify higher degree of concern among the healthcare workers

endangered if a colleague contracted COVID-19 (89\%), feeling at risk of contracting COVID-19 at the workplace (81\%), feeling ashamed disclosing to colleagues if they contracted COVID-19 (79\%), and feeling that they should observe social distancing more than non-HCWs (75\%) (Table 2). Many also reported increased workload (59\%) and inadequate staffing (58\%) as problems. Respondents were least concerned about stigma from their families and COVID-19 standard operating procedures at their workplaces. Approximately one quarter of the respondents reported that they would feel ashamed disclosing to family if they contracted COVID-19 (24\%), felt they should change their job due to COVID-19 risk (23\%), did not feel safe with standard infection prevention and control (IPC) measures (25\%), and were worried about the workplace not having a clear outbreak response plan (26\%) (Table 2).

\section{Level of psychological distress}

The mean GHQ-12 distress score of the HCWs was 12 $(\mathrm{SD} \pm 7.2) ; 144$ had a GHQ-12 score $>12$, yielding a prevalence of psychological distress of 44\% (95\% CI 38-49\%). The most commonly-reported indicators from the GHQ12 questionnaire with a score $>1$ were not enjoying dayto-day activities (54\%), constantly feeling under stress (50\%), not feeling reasonably happy (43\%), and feeling unhappy and depressed (40\%). Approximately three in ten $(29 \%)$ reported losing sleep, and two in ten (22\%) reported feeling worthless (Table 3). 
Table 2 Concerns of healthcare workers with regard to COVID-19 outbreak during the early phase of the epidemic, Uganda, AprilMay $2020(N=328)$

\begin{tabular}{|c|c|c|c|c|}
\hline \multirow[t]{3}{*}{ Concern statement } & \multicolumn{4}{|c|}{ Responses to concern statements $(N=328)$} \\
\hline & \multicolumn{2}{|l|}{ Number } & \multicolumn{2}{|l|}{ Percent } \\
\hline & Low concern & High concern & Low concern & High concern \\
\hline \multicolumn{5}{|l|}{ Fear of contracting COVID-19 at workplace } \\
\hline I would feel endangered if a colleague contracted COVID-19 & 35 & 293 & 11 & 89 \\
\hline I am at risk of contracting COVID-19 & 63 & 265 & 19 & 81 \\
\hline I feel anxious at work & 96 & 233 & 21 & 71 \\
\hline I am unsafe at work & 95 & 232 & 29 & 71 \\
\hline I will eventually get COVID-19 & 191 & 137 & 58 & 42 \\
\hline Being absent will reduce my chances of contracting COVID-19 & 201 & 127 & 61 & 39 \\
\hline I feel helpless about contracting COVID-19 & 213 & 109 & 67 & 33 \\
\hline I feel I should avoid going to work to avoid contracting COVID-19 & 230 & 98 & 70 & 30 \\
\hline I do not feel safe even when I use standard IPC measures & 245 & 83 & 75 & 25 \\
\hline I feel I should change job in future due to COVID-19 risk & 253 & 75 & 77 & 23 \\
\hline \multicolumn{5}{|l|}{ Perceived workplace risks and conditions } \\
\hline My workplace would not support me if I contracted COVID-19 & 120 & 208 & 37 & 63 \\
\hline COVID-19 outbreak has increased my workload & 134 & 194 & 41 & 59 \\
\hline Workload is not matched with staffing needs & 137 & 191 & 42 & 58 \\
\hline There is no adequate PPE & 143 & 185 & 44 & 56 \\
\hline I have not received adequate training on IPC & 189 & 139 & 58 & 42 \\
\hline I feel overwhelmed by new COVID-19 regulations & 193 & 135 & 49 & 41 \\
\hline I am not confident about IPC measures & 216 & 112 & 66 & 34 \\
\hline There is no clear outbreak response plan & 243 & 85 & 74 & 26 \\
\hline \multicolumn{5}{|l|}{ Fear of spreading COVID-19 } \\
\hline I should social distance more than non-HCWs & 82 & 246 & 25 & 75 \\
\hline I will likely transmit COVID-19 to family members & 132 & 196 & 40 & 60 \\
\hline \multicolumn{5}{|l|}{ Stigma against self (internal) and others (external) } \\
\hline I would feel ashamed disclosing to colleagues if I contracted COVID-19 & 69 & 259 & 21 & 79 \\
\hline Family will not look after me if I contract COVID-19 & 153 & 175 & 47 & 53 \\
\hline I feel forced to care for COVID-19 patients & 173 & 155 & 53 & 47 \\
\hline I would feel ashamed disclosing to my family if I contracted COVID-19 & 249 & 79 & 76 & 24 \\
\hline
\end{tabular}

IPC infection control and prevention, HCW healthcare worker, COVID-19 coronavirus disease, PPE personal protective equipment

\section{Factors associated with psychological distress}

Compared to HCWs with a low risk perception score towards COVID-19, the prevalence of psychological distress was significantly higher among those with moderate $(\mathrm{aPR}=2.2 ; 95 \% \mathrm{CI} 1.2-4.0)$ and high $(\mathrm{aPR}=3.8 ; 95 \% \mathrm{CI}$ 2.0-7.0) risk perception towards COVID-19 (Table 4).

In univariable analyses, none of the socio-demographic or occupational factors, including age category, sex, HCW category by patient contact (direct/indirect), duration in service, working hours, having children, or experience providing direct care to a suspected COVID-19 case were significantly associated with psychological distress. Experience providing direct care to a confirmed COVID19 case did not have a significant effect on psychological distress prevalence when controlling for other potential factors, including risk perception score.

\section{Discussion}

We assessed risk perception and psychological state of HCWs based in referral hospitals designated to manage COVID-19 patients in the early phase of the COVID-19 epidemic in Uganda. We found psychological distress in $44 \%$ of the HCWs surveyed in the first two months (April-May 2020) of the epidemic. The level of risk perception towards COVID-19 was directly and independently associated with psychological distress among HCWs.

Reports of psychological distress among HCWs during the COVID-19 pandemic have varied. The prevalence of distress reported in the current study is comparable to the prevalence of psychological distress of $39 \%$ reported among HCWs in China in the early 
Table 3 Frequency of GHQ-12 items among healthcare workers in tertiary referral hospitals during the early phase of the epidemic, Uganda, April-May 2020 ( $N=328)$

\begin{tabular}{lllllll}
\hline Items $^{\dagger}$ from GHQ-12 questionnaire & \multicolumn{6}{c}{$\begin{array}{l}\text { Percentage of score } \\
\text { responses (N= 328) }\end{array}$} \\
\cline { 2 - 7 } & $\mathbf{0}$ & $\mathbf{1}$ & $\mathbf{2}$ & $\mathbf{3}$ & $\mathbf{2}$ or 3* \\
\hline Not enjoying daily activities & 21 & 25 & 25 & 29 & 54 \\
Feeling constantly under stress & 37 & 14 & 22 & 28 & 50 \\
Not feeling reasonably happy & 20 & 37 & 21 & 22 & 43 \\
Feeling unhappy and depressed & 44 & 16 & 17 & 23 & 40 \\
Cannot overcome difficulties & 30 & 32 & 20 & 18 & 38 \\
Cannot concentrate on tasks & 39 & 30 & 20 & 11 & 31 \\
Losing sleep worrying about COVID-19 & 55 & 16 & 8.8 & 20 & 29 \\
Cannot face up to problems & 41 & 34 & 16 & 9.8 & 26 \\
Lost confidence & 61 & 15 & 12 & 13 & 25 \\
Feeling worthless & 70 & 7.9 & 10 & 12 & 22 \\
Not capable of making decisions & 47 & 34 & 15 & 4 & 19 \\
Not feeling useful in society & 73 & 19 & 3.4 & 4.3 & 8
\end{tabular}

*A higher score signifies psychologically-distressed state; GHQ: General health questionnaire

${ }^{\dagger}$ All items were asked about for the period of the past one month

${ }^{\S} \mathrm{GHQ}-12$ items as proposed by Goldberg [19]

phase of the pandemic [1], but much lower than the $72 \%$ prevalence reported among HCWs in high-risk situations in China when the total confirmed cases had already surpassed 10,000 in the country [14]. The lower prevalence of psychological distress in our study compared to China may relate to the fact that none of the HCWs in Uganda had been diagnosed with COVID-19 at the time of the survey [18]. Furthermore, the incidence of COVID-19 was substantially lower in Uganda than in China, which may have accounted for the difference [17]. Notably, we found higher levels of psychological distress among healthcare workers during the COVID-19 pandemic than were reported in Hong Kong (7\%) and Canada (29\%) during the earlier SARS outbreak $[6,29]$. It is possible that the transmissibility of SARS-CoV-2 in the absence of symptoms, which prevents easy identification of infected persons, may have increased the level of concern among HCWs.

We found a strong association between risk perception towards COVID-19 and psychological distress among HCWs in Uganda. This is both expected and consistent with studies of HCWs' distress during outbreaks of other respiratory infectious diseases [1, 25, 27, 34-36]. Others have noted that HCWs' psychological distress can derive from managing the dynamics of challenges to personal safety, fear for others or oneself becoming infected, and altruism and professional responsibility $[15,37]$. Concerns about the safety of HCWs or their families and friends, changes in workplace dynamics, and being isolated can be major sources of distress [38].

Our findings point towards potential interventions to address the concerns of HCWs in Uganda and improve their psychological well-being. About half of respondents reported inadequate PPE availability, while most felt safe when using IPC measures. The fear of contracting infection among HCWs might have been heightened in facilities with inadequate PPE stock and might have increased as PPE was used and shortages were anticipated. To protect the physical and mental health of HCWs, the Ministry of Health $(\mathrm{MoH})$ and facility management may consider maintaining adequate PPE supply and facilitating routine IPC trainings.

More than half of the HCWs also reported increased workloads and inadequate staffing. Employers may consider setting shorter working hours, rotating shifts for HCWs working in high-risk zones, and/or encouraging regular rest periods, when possible, to improve the morale of HCWs during the pandemic [15]. In circumstances where shortening of working hours in epidemics is not a feasible option, employers could consider other options including providing incentive pay for extra hours worked and offering complimentary transportation and food for HCWs on duty. Such practices are particularly important in epidemics that extend several months or even years when HCWs will feel the long-term effects of overworking [15].

Others have also reported that inclusive leadership can alleviate the psychological distress of HCWs [39]. This can mean providing HCWs with opportunities to share their concerns so they can be directly addressed. Most respondents expressed perceived stigma if they had to disclose contracting COVID-19 to colleagues. Supervisors and employers should make deliberate efforts to render more psychosocial support to HCWs who may contract COVID-19 and to regard such infections as work-related injuries. In this context, in which HCWs reported concerns about not being supported by their workplace if they contracted COVID-19, the $\mathrm{MoH}$ or facility management may consider providing HCWs with healthcare and compensation and assure them they would not lose their jobs if they get infected during the epidemic. Additionally, peer support systems for HCWs could be established and HCWs encouraged to utilize them for psychological distress to be identified and addressed in a timely manner without HCWs perceiving stigma or discrimination. These practices could reduce the psychological impact in a healthcare work environment during epidemics [15]. Our findings that a meaningful proportion of the HCWs had insomnia and felt worthless and depressed suggests that the HCWs could experience long-term mental health problems, as 
Table 4 Factors associated with psychological distress among healthcare workers in tertiary referral hospitals during the early phase of the COVID-19 epidemic, Uganda, April-May 2020 ( $N=328)$

\begin{tabular}{|c|c|c|c|c|c|c|}
\hline \multirow[t]{2}{*}{ Characteristic } & \multicolumn{2}{|c|}{ Psychological distress } & \multicolumn{2}{|c|}{ Univariable analysis } & \multicolumn{2}{|l|}{ Multivariable analysis** } \\
\hline & $\begin{array}{l}\text { Distressed } \\
(n=144), \\
n(\%)\end{array}$ & $\begin{array}{l}\text { No distress } \\
(\mathrm{n}=184), \mathrm{n}(\%)\end{array}$ & PR $(95 \% \mathrm{Cl})$ & $P$ value & Adjusted PR (95\% Cl) & $P$ value \\
\hline \multicolumn{7}{|c|}{ Level of concern/risk perception } \\
\hline Low & $13(9.0)$ & $59(32)$ & Ref & & Ref & \\
\hline Moderate & $72(50)$ & $103(56)$ & $2.3(1.3-4.1)$ & 0.006 & $2.2(1.2-4.0)$ & 0.010 \\
\hline High & $59(41)$ & $22(12)$ & $4.0(2.2-7.4)$ & $<0.001$ & $3.8(2.0-7.0)$ & $<0.001$ \\
\hline \multicolumn{7}{|l|}{ Age category } \\
\hline$\leq 35$ years & $73(51)$ & $101(55)$ & Ref & & & \\
\hline$>35$ years & $71(49)$ & $83(45)$ & $1.1(0.79-1.5)$ & 0.571 & & \\
\hline \multicolumn{7}{|l|}{ Sex } \\
\hline Male & $67(47)$ & $105(57)$ & Ref & & Ref & \\
\hline Female & $77(53)$ & $79(43)$ & $1.3(0.98-1.8)$ & 0.156 & $1.2(0.84-1.7)$ & 0.322 \\
\hline \multicolumn{7}{|c|}{ Category of HCW by patient contact } \\
\hline Direct contact & $110(76)$ & $132(72)$ & Ref & & & \\
\hline Indirect contact & $34(24)$ & $52(28)$ & $0.87(0.60-1.3)$ & 0.477 & & \\
\hline \multicolumn{7}{|c|}{ Years of experience } \\
\hline$<5$ years & $46(32)$ & $78(42)$ & Ref & & Ref & \\
\hline $5-10$ years & $43(30)$ & $46(25)$ & $1.3(0.86-2.0)$ & 0.213 & $1.3(0.84-1.9)$ & 0.253 \\
\hline$>10$ years & $55(38)$ & $60(33)$ & $1.3(0.87-1.9)$ & 0.204 & $1.1(0.79-1.6)$ & 0.778 \\
\hline \multicolumn{7}{|c|}{ Hours worked per week } \\
\hline$\leq 40 \mathrm{~h}$ & $58(40)$ & $62(34)$ & Ref & & & \\
\hline$>40 \mathrm{~h}$ & $86(60)$ & $122(66)$ & $0.86(0.61-1.2)$ & 0.358 & & \\
\hline \multicolumn{7}{|c|}{ Number of children } \\
\hline None & $45(31)$ & $58(32)$ & Ref & & & \\
\hline One or more & $99(69)$ & $126(69)$ & $1.0(0.71-1.4)$ & 0.969 & & \\
\hline \multicolumn{7}{|c|}{ Provided direct care for suspected COVID-19 case* } \\
\hline No & $71(49)$ & $71(39)$ & Ref & & & \\
\hline Yes & $73(51)$ & $113(61)$ & $0.78(0.57-1.1)$ & 0.146 & & \\
\hline \multicolumn{7}{|c|}{ Provided direct care for confirmed COVID-19 case } \\
\hline No & $91(63)$ & $86(47)$ & Ref & & Ref & \\
\hline Yes & $53(37)$ & $98(53)$ & $0.68(0.49-0.96)$ & 0.027 & $0.87(0.61-1.2)$ & 0.430 \\
\hline
\end{tabular}

Ref reference category, $\mathrm{Cl}$ confidence interval, $P R$ prevalence ratio, $\mathrm{HCW}$ healthcare worker

*Excluded from multivariable model due to collinearity with provision of direct care to confirmed case

**Adjusted for sex, years of professional experience, and providing direct care to a confirmed COVID-19 case

was observed in similar previous outbreaks including the 2003 SARS outbreak [40]. We recommend followup studies to assess mental health outcomes related to COVID-19 among the HCWs, in order to inform timely interventions. In the meantime, the $\mathrm{MoH}$ may consider setting up psychological support networks nationwide including internet-, or telephone-based counselling/ treatment services targeting HCWs as part of an epidemic response.

Our findings are subject to three main limitations. First, we relied on self-report of psychological status and risk perception, so these findings may be prone to response bias including social desirability bias, although this was minimized by using self-administered questionnaires. This may have led to underestimation of the prevalence of psychological distress in the study population, and potentially biased our associations towards null. Second, we included only the day-shift employees available at our visits. These represented approximately one-third of HCWs at the facilities and may not be representative of all employees at the hospitals. Third, our study lacked a comparison group of HCWs in hospitals that were not treating COVID-19 patients at the time; we were, therefore, unable to compare the level of psychological distress 
between the two groups. Despite these limitations, our survey provided useful information to the $\mathrm{MoH}$ on the psychological state of HCWs and highlighted their key concerns in the first two months of the COVID-19 outbreak in Uganda; this informed designing of evidence-based measures to improve HCWs' psychological well-being during the pandemic, especially by improving supplies of PPE and conducting IPC trainings to HCWs.

\section{Conclusion}

About half of the HCWs surveyed in the early phase of the COVID-19 epidemic in Uganda reported psychological distress even before any HCWs in Uganda had contracted COVID-19. The perceived personal risk was associated with psychological distress, so reducing perceived risks might enhance HCWs' physical and psychological well-being. This work reveals several HCWs' concerns that might be addressed to improve the psychological health of HCWs during this ongoing pandemic and in future epidemics. This might be accomplished by ensuring sufficient PPE and access to IPC training, improving morale, addressing stigma in the workplace and in the community, and rendering more psychosocial support by employers and supervisors. Follow-up studies in different phases during and after the COVID-19 pandemic might further reveal impacts of COVID-19 on HCWs' stress and the effectiveness of practices aimed at strengthening their mental health and occupational safety; such psychological distress may interfere with the effective implementation and sustainability of health services. Qualitative interviews might particularly help elucidate the nature and extent of the psychological impact of the COVID-19 pandemic on HCWs.

\section{Abbreviations \\ Cl: Confidence interval; COVID-19: Coronavirus Disease; GHQ: General health questionnaire; HCW: Healthcare worker; IQR: Inter-quartile Range; MoH: Ministry of Health; PPE: Personal protective equipment; PR: Prevalence ratio; SARS-CoV-2: Severe Acute Respiratory Syndrome Coronavirus 2; SD: Standard Deviation.}

\section{Acknowledgements}

We thank the HCWs who participated in this study. We are also grateful to the support from the administration of Mulago National Referral Hospital, Entebbe Grade B Hospital, Arua Regional Referral Hospital, Jinja Regional Referral Hospital, and Kabale Regional Referral Hospital for their support in conducting this investigation.

\section{Authors' contributions}

RM, IW, BK, LB, DK, SNK, EK, AN, GA, RH, AGF, and ARA contributed to study design and drafting of the first manuscript. RM, EK and AGF did formal analyses. RM, IW, EK, AN, GA, and AB contributed to data collection. JRH, ARA and AGF contributed to interpretation of findings. All authors contributed to the write up. All authors read and approved the final manuscript.

\section{Funding}

This project was supported by the President's Emergency Plan for AIDS Relief (PEPFAR) through the US Centers for Disease Control and Prevention
Cooperative Agreement number GH001353-01 through Makerere University School of Public Health to the Uganda Public Health Fellowship Program, $\mathrm{MoH}$. Its contents are solely the responsibility of the authors and do not necessarily represent the official views of the US Centers for Disease Control and Prevention, the US Department of Health and Human Services, Makerere University School of Public Health, or the MoH. The staff of the funding body provided technical guidance in the design of the study, ethical clearance and collection, analysis, and interpretation of data and in writing the manuscript.

\section{Availability of data and materials}

The datasets upon which our findings are based belong to the Uganda Public Health Fellowship Program. For confidentiality reasons, the datasets are not publicly available. However, the data sets can be availed upon reasonable request from the corresponding author and with permission from the Uganda Public Health Fellowship Program.

\section{Declarations}

\section{Ethics approval and consent to participate}

This was a public health emergency and the Ministry of Health $(\mathrm{MoH})$ gave the authorization to conduct the study on the psychological impact of COVID-19 among HCWs. We, however, sought and obtained written informed consent from respondents during data collection. The participants indicated their consent by checking an appropriate box for consent before filling the questionnaires. Participants were told that their participation was voluntary and that there would be no negative consequences if they refused to participate (none declined). During data collection, respondents were assigned unique identifiers instead of names to protect their confidentiality. Information was stored in password-protected computers and was not shared with anyone outside the investigation team. Additionally, we obtained permission from the directors of the respective hospitals prior to conducting the study. The Office of Science, U.S. Centers for Disease Control and Prevention, determined that this activity was in response to a public health emergency with the primary intent of public health practice (epidemic disease control activity). It was determined, therefore, to not be human subjects' research.

\section{Consent for publication}

Not applicable.

\section{Competing interests}

The authors declare no competing interests.

\section{Author details}

${ }^{1}$ Uganda Public Health Fellowship Program, Kampala, Uganda. ${ }^{2}$ Ministry of Health, Kampala, Uganda. ${ }^{3}$ COVID-19 Response International Task Force, US Centers for Disease Control and Prevention, Kampala, Uganda.

Received: 22 July 2021 Accepted: 14 December 2021

Published online: 17 December 2021

\section{References}

1. Dai Y, Hu G, Xiong H, Qiu H, Yuan X. Psychological impact of the coronavirus disease 2019 (COVID-19) outbreak on healthcare workers in China. medRxiv. 2020:2020.03.03.20030874.

2. Koh D, Lim MK, Chia SE. SARS: health care work can be hazardous to health. Occup Med. 2003;53(4):241-3.

3. Maunder R, Hunter J, Vincent L, Bennett J, Peladeau N, Leszcz M, et al. The immediate psychological and occupational impact of the 2003 SARS outbreak in a teaching hospital. Can Med Assoc J. 2003;168(10):1245-51.

4. Bai Y, Lin C-C, Lin C-Y, Chen J-Y, Chue C-M, Chou P. Survey of stress reactions among health care workers involved with the SARS outbreak. Psychiatr Serv. 2004;55(9):1055-7.

5. Lee AM, Wong JG, MCAlonan GM, Cheung V, Cheung C, Sham PC, et al. Stress and psychological distress among SARS survivors 1 year after the outbreak. Can J Psychiatry. 2007;52(4):233-40. 
6. Chua SE, Cheung V, Cheung C, McAlonan GM, Wong JW, Cheung EP, et al. Psychological effects of the SARS outbreak in Hong Kong on high-risk health care workers. Can J Psychiatry. 2004;49(6):391-3.

7. Jalloh MF, Li W, Bunnell RE, Ethier KA, O'Leary A, Hageman KM, et al. Impact of Ebola experiences and risk perceptions on mental health in Sierra Leone, July 2015. BMJ Glob Health. 2018;3(2):e000471.

8. Burton WN, Schultz AB, Chen CY, Edington DW. The association of worker productivity and mental health: a review of the literature. Int J Workplace Health Manag. 2008.

9. Stuijfzand S, Deforges C, Sandoz V, Sajin C-T, Jaques C, Elmers J, et al. Psychological impact of an epidemic/pandemic on the mental health of healthcare professionals: a rapid review. BMC Public Health, 2020;20(1):1230.

10. Ofori AA, Osarfo J, Agbeno EK, Manu DO, Amoah E. Psychological impact of COVID-19 on health workers in Ghana: a multicentre, cross-sectional study. SAGE Open Med. 2021;9:20503121211000920.

11. Que J, Le Shi JD, Liu J, Zhang L, Wu S, Gong Y, et al. Psychological impact of the COVID-19 pandemic on healthcare workers: a cross-sectional study in China. Gener Psychiatry. 2020;33(3):e100259.

12. Cabarkapa S, Nadjidai SE, Murgier J, Ng CH. The psychological impact of COVID-19 and other viral epidemics on frontline healthcare workers and ways to address it: a rapid systematic review. Brain Behav Immun Health. 2020;25:100144

13. Khanal P, Devkota N, Dahal M, Paudel K, Joshi D. Mental health impacts among health workers during COVID-19 in a low resource setting: a cross-sectional survey from Nepal. Glob Health. 2020;16(1):1-12.

14. Lai J, Ma S, Wang Y, Cai Z, Hu J, Wei N, et al. Factors associated with mental health outcomes among health care workers exposed to coronavirus disease 2019. JAMA Netw Open. 2020;3(3):e203976-e.

15. Ho CS, Chee CY, Ho RC. Mental health strategies to combat the psychological impact of COVID-19 beyond paranoia and panic. Ann Acad Med Singapore. 2020;49(1):1-3.

16. Wemos and ACHEST. Country report Uganda | Uganda's human resources for health: paradoxes and dilemmas Kampala; 2019.

17. Migisha R, Kwesiga B, Mirembe BB, Amanya G, Kabwama SN, Kadobera D, et al. Early cases of SARS-CoV-2 infection in Uganda: epidemiology and lessons learned from risk-based testing approaches-March-April 2020. Glob Health. 2020;16(1):1-9.

18. Health Mo. Update on the COVID-19 outbreak in Uganda Kampala; 2020 https://www.health.go.ug/covid/document/update-on-the-covid-19outbreak-in-uganda-12/.

19. Wu Z, McGoogan JM. Characteristics of and important lessons from the coronavirus disease 2019 (COVID-19) outbreak in China: summary of a report of 72314 cases from the Chinese center for disease control and prevention. J Am Med Assoc. 2020;323(13):1239-42.

20. Zhan M, Qin Y, Xue X, Zhu S. Death from Covid-19 of 23 health care workers in China. N Engl J Med. 2020;382(23):2267-8.

21. Team CC-R. Characteristics of Health Care Personnel with COVID19-United States, February 12-April 9, 2020. Morb Mortal Weekly Rep. 2020;69(15):477-81.

22. Paterlini M. On the front lines of coronavirus: the Italian response to covid-19. BMJ. 2020;368:m1065.

23. Bandyopadhyay S, Baticulon RE, Kadhum M, Alser M, Ojuka DK, Badereddin Y, et al. Infection and mortality of healthcare workers worldwide from COVID-19: a scoping review. medRxiv. 2020.

24. Moorthy A, Sankar TK. Emerging public health challenge in UK: perception and belief on increased COVID19 death among BAME healthcare workers. J Public Health. 2020;42(3):486-92.

25. Wong TY, Koh G, Cheong SK, Lee HY, Fong YT, Sundram M, et al. Concerns, perceived impact and preparedness in an avian influenza pandemic-a comparative study between healthcare workers in primary and tertiary care. Ann Acad Med Singapore. 2008:37(2):96-102.

26. Koh D, Lim MK, Chia SE, Ko SM, Qian F, Ng V, et al. Risk perception and impact of severe acute respiratory syndrome (SARS) on work and personal lives of healthcare workers in Singapore: what can we learn? Med Care. 2005:43(7).

27. Abolfotouh MA, AIQarni AA, Al-Ghamdi SM, Salam M, Al-Assiri MH, Balkhy $\mathrm{HH}$. An assessment of the level of concern among hospital-based healthcare workers regarding MERS outbreaks in Saudi Arabia. BMC Infect Dis. 2017;17(1):4.
28. Goldberg DP. The detection of psychiatric illness by questionnaire. Maudsley Monogr. 1972;21.

29. Nickell LA, Crighton EJ, Tracy CS, Al-Enazy H, Bolaji Y, Hanjrah S, et al. Psychosocial effects of SARS on hospital staff: survey of a large tertiary care institution. Can Med Assoc J. 2004;170(5):793-8.

30. Shoja E, Aghamohammadi V, Bazyar H, Moghaddam HR, Nasiri K, Dashti $M$, et al. Covid-19 effects on the workload of Iranian healthcare workers. BMC Public Health. 2020;20(1):1636.

31. Bettinsoli ML, Di Riso D, Napier JL, Moretti L, Bettinsoli P, Delmedico $M$, et al. Mental Health Conditions of Italian Healthcare Professionals during the COVID-19 Disease Outbreak. Appl Psychol Health Wellbeing. 2020;12(4):1054-73.

32. Montazeri A, Harirchi AM, Shariati M, Garmaroudi G, Ebadi M, Fateh A. The 12-item General Health Questionnaire (GHQ-12): translation and validation study of the Iranian version. Health Qual Life Outcomes. 2003;1 (1):66.

33. Goldberg DP, Gater R, Sartorius N, Ustun TB, Piccinelli M, Gureje O, et al. The validity of two versions of the GHQ in the WHO study of mental illness in general health care. Psychol Med. 1997;27(1):191-7.

34. Wu P, Fang Y, Guan Z, Fan B, Kong J, Yao Z, et al. The psychological impact of the SARS epidemic on hospital employees in China: exposure, risk perception, and altruistic acceptance of risk. Can J Psychiatry. 2009;54(5):302-11.

35. Tai DY. SARS plague: duty of care or medical heroism? Ann Acad Med Singapore. 2006;35(5):374-8.

36. Ehrenstein BP, Hanses F, Salzberger B. Influenza pandemic and professional duty: family or patients first? A survey of hospital employees. BMC Public Health. 2006;6(1):311.

37. Tiong WW, Koh GC. Ethical considerations in the review of Singapore's H1N1 pandemic response framework in 2009. Ann Acad Med Singapore. 2013;42(5):246-50.

38. Wong TW, Yau JKY, Chan CLW, Kwong RSY, Ho SMY, Lau CC, et al. The psychological impact of severe acute respiratory syndrome outbreak on healthcare workers in emergency departments and how they cope. Eur J Emerg Med. 2005;12(1):13-8.

39. Zhao F, Ahmed F, Faraz NA. Caring for the caregiver during COVID-19 outbreak: does inclusive leadership improve psychological safety and curb psychological distress? A cross-sectional study. Int J Nurs Stud. 2020;110:103725.

40. Maunder RG, Lancee WJ, Balderson KE, Bennett JP, Borgundvaag B, Evans $\mathrm{S}$, et al. Long-term psychological and occupational effects of providing hospital healthcare during SARS outbreak. Emerg Infect Dis. 2006;12(12):1924-32.

\section{Publisher's Note}

Springer Nature remains neutral with regard to jurisdictional claims in published maps and institutional affiliations.

Ready to submit your research? Choose BMC and benefit from:

- fast, convenient online submission

- thorough peer review by experienced researchers in your field

- rapid publication on acceptance

- support for research data, including large and complex data types

- gold Open Access which fosters wider collaboration and increased citations

- maximum visibility for your research: over 100M website views per year

At BMC, research is always in progress.

Learn more biomedcentral.com/submissions 